\title{
Harnessing NK cells for cancer immunotherapy: immune checkpoint receptors and chimeric antigen receptors
}

\author{
Nayoung Kim ${ }^{1,2, \#}$, Dong-Hee Lee ${ }^{1,2, \#}$, Woo Seon Choi, ${ }^{3,4, \#}$, Eunbi $\mathrm{Yi}^{3,4}$, HyoJeong Kim ${ }^{3,4}$, Jung Min Kim ${ }^{3}$, Hyung-Seung Jin ${ }^{1,2}$ \\ E Hun Sik Kim ${ }^{3,4,5, *}$ \\ ${ }^{1}$ Department of Convergence Medicine and ${ }^{2}$ Asan Institute for Life Sciences, Asan Medical Center, University of Ulsan College of Medicine, \\ Seoul 05505, ${ }^{3}$ Department of Biomedical Sciences, ${ }^{4}$ Stem Cell Immunomodulation Research Center (SCIRC), ${ }^{5}$ Department of Microbiology, \\ Asan Medical Center, University of Ulsan College of Medicine, Seoul 05505, Korea
}

\begin{abstract}
Natural killer (NK) cells, key antitumor effectors of the innate immune system, are endowed with the unique ability to spontaneously eliminate cells undergoing a neoplastic transformation. Given their broad reactivity against diverse types of cancer and close association with cancer prognosis, NK cells have gained considerable attention as a promising therapeutic target for cancer immunotherapy. NK cell-based therapies have demonstrated favorable clinical efficacies in several hematological malignancies but limited success in solid tumors, thus highlighting the need to develop new therapeutic strategies to restore and optimize anti-tumor activity while preventing tumor immune escape. The current therapeutic modalities yielding encouraging results in clinical trials include the blockade of immune checkpoint receptors to overcome the immune-evasion mechanism used by tumors and the incorporation of tumor-directed chimeric antigen receptors to enhance NK cell anti-tumor specificity and activity. These observations, together with recent advances in the understanding of NK cell activation within the tumor microenvironment, will facilitate the optimal design of NK cell-based therapy against a broad range of cancers and, more desirably, refractory cancers. [BMB Reports 2021; 54(1): 44-58]
\end{abstract}

\section{INTRODUCTION}

Immune checkpoint receptors, such as programmed cell death protein 1 (PD-1) and cytotoxic T-lymphocyte-associated protein 4 (CTLA-4), have recently emerged as molecular targets for

*Corresponding author. Tel: +82-2-3010-2207; Fax: +82-2-3010-5307; E-mail: hunkim@amc.seoul.kr

${ }^{\#}$ These authors contributed equally to this work.

https://doi.org/10.5483/BMBRep.2021.54.1.214

Received 29 September 2020, Revised 23 November 2020, Accepted 3 December 2020

Keywords: Cancer immunotherapy, Chimeric antigen receptors, Immune checkpoint receptors, Immune escape, Natural killer cells cancer immunotherapy (1). Even before the investigation of the importance of such receptors in T cells $(2,3)$, the foundation of NK cell immunology was established by determining the quintessential roles of killer cell immunoglobulin-like receptors (KIRs), the inhibitory receptors in human NK cells. In 1986, Kärre et al. proposed the "missing-self" hypothesis (4). NK cells kill major histocompatibility complex (MHC) class I-deficient tumor cells but fail to kill MHC class l-expressing tumor cells. The recognition of "missing-self" MHC class I is mediated by KIRs in humans and Ly49s in mice. Later, Kim et al. suggested that "licensing" of NK cells is also mediated by the interaction between Ly49s and MHC class I (5). Licensing is a host MHC class I-dependent functional maturation process. Only NK cells that are licensed by self-MHC class I molecules during development are fully functional. Licensing also occurs in human NK cells (6). Thus, immune checkpoint receptors are fundamental for determining NK cell functionality. Nonetheless, NK cells express multiple immune checkpoint receptors, including natural killer group 2A (NKG2A), CTLA-4, PD-1, T cell immunoglobulin mucin 3 (TIM-3), and T cell immunoreceptor with Ig and immunoreceptor tyrosine-based inhibition motif (ITIM) domains (TIGIT), which have been explored as promising therapeutic targets to enhance the specificity and activity of NK cells against a broad range of cancers.

Another promising cancer treatment modality that has raised considerable interest is the incorporation of tumor-directed chimeric antigen receptors (CARs) in immune effector cells. The clinical success of Kymriah ${ }^{\mathbb{R}}$ and Yescarta ${ }^{\circledR}$, two CAR-T cell therapies targeting hematologic malignancies, is sure to promote the growth of CAR-T cell therapies in clinical trials, thereby treating a range of cancers. Nevertheless, the limitations of CAR-T cell therapies, in terms of off-the-shelf utility, safety, and target antigen escape, necessitate alternatives. With an array of innate receptors responding to cellular transformation, NK cells can efficiently kill a range of tumor cells without $\mathrm{MHC}$ restriction, thereby complementing MHC-restricted tumor lysis by cytotoxic T cells. With radical differences in tumor cell recognition, cytokine production profile, and in vivo persistence, NK-CAR cell therapies are viewed as an attractive alternative or complement to CAR-T cell therapies, as they poten-

ISSN: 1976-670X (electronic edition)

Copyright (c) 2021 by the The Korean Society for Biochemistry and Molecular Biology

(c) This is an open-access article distributed under the terms of the Creative Commons Attribution Non-Commercial License (http://creativecommons.org/licenses/by-nc/4.0) which permits unrestricted non-commercial use, distribution, and reproduction in any medium, provided the original work is properly cited. 
tially overcome several clinical challenges presented by CAR-T cell therapies. In this review, we summarize recent advances in NK cell-based cancer immunotherapy with a focus on immune checkpoint receptors, some of which are unique to NK cells and CAR-NK cells.

\section{IMMUNE CHECKPOINT RECEPTORS}

\section{KIR, LIR, and CD94/NKG2A}

Inhibitory KIRs, i.e. 2DL1, 2DL2, 2DL3, 2DL5, 3DL1, 3DL2, and 3DL3, have long cytoplasmic tails comprising two ITIMs (7). Inhibitory KIRs recognize human leukocyte antigen (HLA)-A, $\mathrm{B}$, or C (Fig. 1). The main roles of KIRs in NK cells are described above. They have highly polymorphic immunoglobulin (Ig) domains specific to HLA molecules (8). Multiple myeloma (MM) cells upregulate MHC class I molecules, thus blocking inhibitory KIRs could enhance the antitumor effect of NK cells in MM. Treatment with anti-KIR2D antibody (Ab) (Lirilumab; IPH2102) has been proven safe without mediating toxicity and autoimmunity in patients with $\mathrm{MM}$ and acute myeloid leukemia (AML) $(9,10)$. Anti-KIR Ab treatment enhanced ex vivo NK cytotoxicity in patients with $\mathrm{MM}$, but the Phase II clinical trial of lirilumab in MM resulted in failure due to lack of efficacy

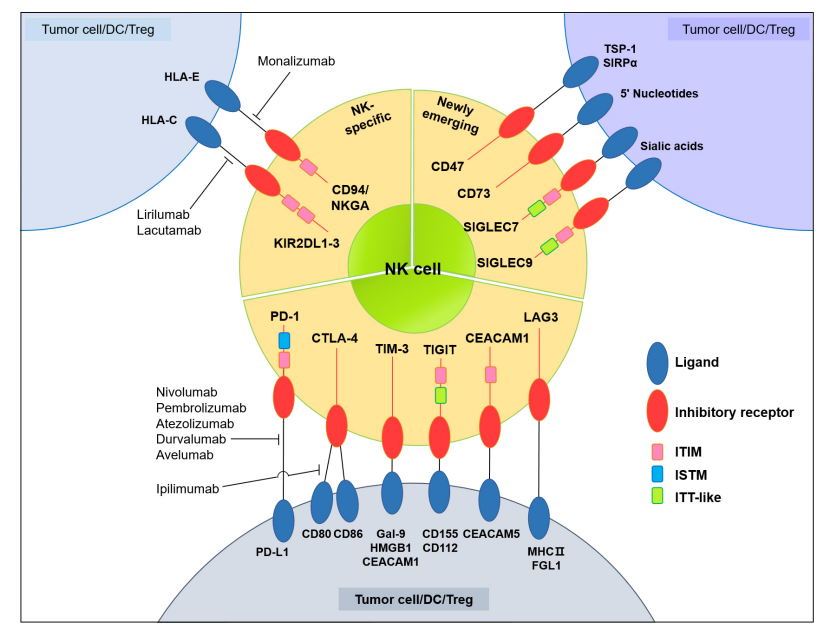

Fig. 1. Interactions between immune checkpoint receptors and their cognate ligands. NK cells express multiple immune checkpoint receptors, which can interact with their cognate ligands on tumor cells as well as other immune cells, in particular, dendritic cells and Tregs. The red circles represent immune checkpoint receptors while the blue circles represent the ligands. SIGLEC7 and SIGLEC9 have common ligands that are sialic acids. The pink squares represent the classical ITIM motif and the light blue squares represent the ITSM motif, which have been implicated in mediating inhibitory signals. The light green squares represent the ITT-like motif. Cytoplasmic domains of other immune checkpoint receptors contain fewer known motifs (not marked as squares). CD73 is a nucleotidase, which does not have conventional inhibitory signaling domains. The black lines indicate receptor-ligand interactions. and presumably a loss of KIR2D expression in NK cells (11). Anti-KIR Abs have been tested alone or in combination with other therapeutics, including lenalidomide, anti-CD20 Ab (rituximab), and immune checkpoint blockades in various hematological disorders, including MM, lymphoma, and myelodysplastic syndromes (12-15). The latest addition to this group is lacutamab (IPH4102), a first-in-class anti-KIR3DL2 Ab. It has been demonstrated to be safe, and $36 \%$ of patients with relapsed/refractory cutaneous T cell lymphoma responded to it in a Phase I trial (16). Apart from immune checkpoint blockade, pre-treatment with IL-12/15/18 reduces the expression of KIRs in NK cells and enhances NK cytotoxicity against tumor cells (17), suggesting that ex vivo expanded NK cells could be potent anti-tumor therapeutics by themselves or as CAR bearers. Clinical trials using immune checkpoint blockade are summarized in Table 1.

Among leukocyte immunoglobulin-like receptors (LIRs), LIR-1, also known as LIR subfamily B member 1 (LIRB-1), immunoglobulin-like transcript 2 (ILT2), and CD85j, recognizes HLA-G, a non-classical MHC class I molecule. LIR-1 contains ITIM motifs to recruit phosphatases, such as SHP-1 (18). HLA-G is expressed in various tumors and is often associated with reduced NK function or progressive tumors (19). Soluble HLA-G (sHLA-G) also plays a role in mediating regulatory function in some tumors, such as thyroid and colorectal cancers $(20,21)$. Blocking LIR-1 alone did not enhance the cytotoxicity of NK cells against MM cells (22), but a dual blockade of LIR-1 and NKG2A increased the cytotoxicity of $\mathrm{KIR}^{-} \mathrm{NK}$ cells against acute leukemic cells in vitro (23). NKG2A is well known as an HLA-E receptor but has recently been suggested as an HLA-G receptor (24). However, the action mechanisms for the dual blockade may require further investigation.

CD94/NKG2A is a heterodimeric inhibitory receptor related to C-type lectins, recognizing another non-classical MHC class I molecule, HLA-E. ITIMs are phosphorylated upon receptor engagement and recruit tyrosine phosphatases SHP-1 and SHP-2 $(25,26)$. SHP-1 mediates dephosphorylation of Vav1 (27). In addition, Crk phosphorylation contributes to the inhibition of NK cells through NKG2A-HLA-E interaction (28). ITIM-based inhibition appears to be dominant over activation in NK cells against normal cells. Recruitment of SHP-1 by MHC-I-specific ITIM-bearing receptors inhibited signaling at a proximal step, such that most downstream signals were prevented (29). HLA-E is overexpressed in human colorectal cancers with poor prognosis (30). Ovarian and cervical cancer cells express HLA-E that limits $\mathrm{NKG}_{2} \mathrm{~A}^{+}$cytotoxic $\mathrm{T}$ cells, thereby resulting in less infiltration of NK cells in HLA-E-expressing gynecological cancer (31). In addition, NKG2 $\mathrm{A}^{-} \mathrm{NKG} 2 \mathrm{C}^{+} \mathrm{KIR}^{+} \mathrm{CD} 56^{\mathrm{dim}} \mathrm{NK}$ cells are suggested as memory-like $\mathrm{NK}$ cells in patients with human cytomegalovirus infection (32). An anti-NKG2A Ab (monalizumab; IPH2201) ameliorates NK cell dysfunction in chronic lymphocytic leukemia (33). Monalizumab is currently under clinical investigation as a single agent in ovarian cancer or in combination with cetuximab (anti-EGFR $\mathrm{Ab}$ ) and durvalumab 
Table 1. Current status of clinical trials based on immune checkpoint receptors

\begin{tabular}{|c|c|c|c|c|c|}
\hline Checkpoint receptor & Ab/drug & Combination drugs & Disease & Phase & Clinical trials identifier \\
\hline \multirow[t]{5}{*}{ KIRs } & \multirow{2}{*}{$\begin{array}{l}\text { Anti-KIR } \\
\quad(1-7 F 9, \text { IPH2101) }\end{array}$} & Single & MM & Phase I & NCT00552396 \\
\hline & & Single & MM, SMM & Phase II & NCT01248455 \\
\hline & \multirow{3}{*}{$\begin{array}{l}\text { Lirilumab } \\
\text { (IPH2102, } \\
\text { BMS-986015) }\end{array}$} & Lenalidomide & $\mathrm{MM}$ & Phase I & NCT01217203 \\
\hline & & $\begin{array}{l}\text { Nivolumab, } \\
\text { Azacitidine }\end{array}$ & MDS & Phase II & NCT02599649 \\
\hline & & Single & Gynecologic cancer & Phase I & NCT02459301 \\
\hline \multirow[t]{3}{*}{ CD94/NKG2A } & \multirow[t]{3}{*}{$\begin{array}{l}\text { Monalizumab } \\
\text { (IPH2201) }\end{array}$} & $\begin{array}{l}\text { Durvalumab } \\
\text { (MEDI4736) }\end{array}$ & Advanced solid tumors & Phase I/II & NCT02671435 \\
\hline & & $\begin{array}{l}\text { Cetuximab, } \\
\text { Anti-PD-L1 }\end{array}$ & Head and neck carcinoma & Phase I/II & NCT02643550 \\
\hline & & Ibrutinib & CLL & Phase I/II & NCT02557516 \\
\hline \multirow[t]{3}{*}{ CTLA-4 } & \multirow{3}{*}{$\begin{array}{l}\text { Ipilimumab } \\
\text { (BMS-734016) }\end{array}$} & Single & Advanced melanoma & Phase I & NCT00920907 \\
\hline & & Nivolumab & $\begin{array}{l}\text { Advanced/metastatic } \\
\text { melanoma }\end{array}$ & Phase II & NCT01783938 \\
\hline & & $\begin{array}{l}\text { Paclitaxel, } \\
\text { Cisplatin, } \\
\text { Carboplatin }\end{array}$ & NSCLC & Phase II & NCT01820754 \\
\hline \multirow[t]{3}{*}{ PD-1 } & $\begin{array}{l}\text { Pembrolizumab } \\
\text { (MK-3475) }\end{array}$ & Single & Hepatocellular carcinoma & Phase II & NCT02658019 \\
\hline & Nivolumab & Ipilimumab & $\begin{array}{l}\text { Advanced/metastatic } \\
\text { melanoma }\end{array}$ & Phase II & NCT01783938 \\
\hline & $\begin{array}{l}\text { Durvalumab } \\
\text { (MEDI4736) }\end{array}$ & Tremelimumab & $\begin{array}{l}\text { Metastatic pancreatic ductal } \\
\text { adenocarcinoma }\end{array}$ & Phase II & NCT02558894 \\
\hline \multirow[t]{2}{*}{ TIM-3 } & BGB-A425 & Tislelizumab & $\begin{array}{l}\text { Advanced or } \\
\text { metastatic solid tumors }\end{array}$ & Phase I/II & NCT03744468 \\
\hline & MBG453 & $\begin{array}{l}\text { Decitabine, } \\
\text { PDR001 }\end{array}$ & $\mathrm{AML}$ and high risk MDS & Phase I & NCT03066648 \\
\hline TIGIT & MTIG7192A & $\begin{array}{l}\text { Atezolizumab, } \\
\text { Carboplatin, } \\
\text { Cisplatin, } \\
\text { Pemetrexed, } \\
\text { Paclitaxel, } \\
\text { Etoposide }\end{array}$ & Advanced/metastatic tumors & Phase I & NCT02794571 \\
\hline \multirow[t]{2}{*}{ LAG-3 } & \multirow{2}{*}{$\begin{array}{l}\text { LAC-3-Ig } \\
\quad(\text { IMP321) }\end{array}$} & Single & Metastatic breast cancer & Phase I & NCT00349934 \\
\hline & & Montanide ISA-51 & Melanoma & Phase I/II & NCT01308294 \\
\hline CD47 & IBI188 & Single & Advanced malignancies & Phase I & NCT03763149 \\
\hline \multirow[t]{2}{*}{ CD73 } & $\begin{array}{l}\text { Oleclumab } \\
\text { (MEDI9447) }\end{array}$ & $\begin{array}{l}\text { Paclitaxel, } \\
\text { Carboplatin, } \\
\text { Durvalumab }\end{array}$ & Triple negative breast cancer & Phase I/II & NCT03616886 \\
\hline & $\begin{array}{l}\text { Ciforadenant } \\
\text { (CPI-444) }\end{array}$ & Pembrolizumab & Advanced cancer & Phase I & NCT03454451 \\
\hline CD33 (Siglec 3) & $\begin{array}{l}\text { Vadastuximab talirine } \\
\text { (SGN-CD33A) }\end{array}$ & $\begin{array}{l}\text { Azacitidine, } \\
\text { Decitabine, } \\
\text { Placebo }\end{array}$ & AML & Phase III & NCT02785900 \\
\hline
\end{tabular}

MM, multiple myeloma; SMM, smoldering multiple myeloma; AML, acute myeloid leukemia; MDS, myelodysplastic syndromes; CLL, chronic lymphocytic leukemia; NSCLC, non-small cell lung cancer; MBC, metastatic breast carcinoma.

(anti-PD-L1 Ab) for advanced stage solid cancers (34, 35). Interim results of a Phase II trial of monalizumab and cetuximab in previously treated squamous cell head and neck cancer showed a $31 \%$ objective response rate, where monalizumab improved anti-tumor immunity of $\mathrm{T}$ and NK cells (36). A combination of monalizumab and durvalumab demonstrated clinical efficacy and manageable toxicity in a Phase I trial of heavily pretreated metastatic microsatellite colorectal cancer (19). However, NKG2A blockade reportedly works through CD8 T cells rather than NK cells in mouse models that are set to block NKG2A/Qa-1b interaction using HPV16 E6 and E7-expressing tumors (37). Taken together, NKG2A blockade 
appears to be a promising immune-oncological therapeutic that promotes T and/or NK cell activation. Notably, NKG2A can recognize HLA-G as well (24), thereby suggesting the previously unexpected benefit of NKG2A blockade in tumor immunity.

\section{CTLA-4 and PD-1}

CTLA-4 plays a pivotal role in T cell expansion, whereas PD-1 is a central regulator of T cell effector function. CD80 (B7-1) and CD86 (B7-2) are the common ligands for the costimulatory receptor $\mathrm{CD} 28$ as well as the co-inhibitory receptor CTLA-4. However, CTLA-4 binds to ligands with greater affinity than CD28. Despite the absence of inhibitory ITIM, CTLA-4 inhibits the activation of Akt but not PI3K via activating the serine/threonine phosphatase PP2A (38). Engagement of CTLA-4 with $\mathrm{CD} 80$ leads to the reduction in IFN- $\gamma$ production by mouse activated NK cells against mature dendritic cells (39). In head and neck cancer, CTLA-4 is upregulated on Treg cells that suppress NK cell anti-tumor cytotoxicity (40). In melanoma, anti-CTLA-4 treatment leads to Fc receptor-mediated selective depletion of Treg cells $(41,42)$. Moreover, clinical outcome of CTLA-4 therapy in melanoma is associated with the increased population of mature circulating $\mathrm{CD} 3{ }^{-} \mathrm{CD} 56^{\mathrm{dim}} \mathrm{CD} 16^{+} \mathrm{NK}$ cells (43). Thus, anti-CTLA-4 therapy may enhance anti-tumor cytotoxicity of NK cells in both a direct and indirect manner such as depletion of CTLA- $4^{+}$Treg cells. Triple immunotherapy with anti-CTLA4 antibodies, monophosphoryl-lipid-A, and indolamine-dioxygenase-1 inhibitor has been reported to enhance $\mathrm{NK}$ cell counts and the $\mathrm{CD}^{+}{ }^{+} \mathrm{CD} 4{ }^{+} /$Treg and $\mathrm{CD} 3{ }^{+} \mathrm{CD} 8{ }^{+} /$Treg ratios, in addition to the reduction in tumor mass, in a murine melanoma model (44). Combination therapies could provide additional benefits, although the B7/CTLA-4 axis may not play a key role in NK cell activation $(45,46)$.

PD-1 has one ITIM and one immunoreceptor tyrosine-based switch motif (ITSM) in its cytoplasmic domain. Specifically, the ITSM tyrosine (Y248) of PD-1 is known to recruit phosphatase SHP-2, which is mandatory for PD-1-mediated inhibition of the PI3K/Akt pathway (47). The cognate ligands for PD-1 are PD-L1 (B7-H1) and PD-L2 (B7-DC). PD-1 expression is found on $\mathrm{CD} 56^{\mathrm{dim}} \mathrm{NKG} 2 \mathrm{~A}^{-} \mathrm{KIR}^{+} \mathrm{CD} 57^{+}$mature NK cells, but not on CD56 bright $N K$ cells (48). In ovarian cancer and Kaposi sarcoma, PD-1 expression is elevated on NK cells and associated with impaired NK cell function $(49,50)$. PD- $1^{+}$NK cells are considered to be functionally exhausted (32). Blockade of PD-1 enhances cytotoxicity of NK cells against autologous MM cells (51). In Hodgkin lymphoma and diffuse large B-cell lymphoma, PD-1 blocking also reverses the suppression of PD $-1^{+}$NK cells mediated by tumor-associated macrophagelike monocytes (52). In mice, tumor-infiltrated NK cells express PD-1, which suppresses NK cytotoxicity (53). PD-1/PD-L1 blockade, PD-1/PD-L1 genetic deficiency, or NK cell depletion prevents lung metastasis in a B16 melanoma model and tumor growth in a murine model using CT26 colon tumor cells and a breast cancer orthotopic model using 4T1 cells in vivo (53). However, activated human primary NK cells efficiently killed colorectal cancer cells in organoid culture independently of PD-L1 expression (54), and blockade of PD-L1 failed to increase cytotoxicity of human liver-associated NK cells against hepatocellular carcinoma cell lines in vitro (55). In line with these results, PD-1 is expressed only minimally in mouse and human NK cells in various infections and tumor models (56). Nevertheless, PD-1 expression in murine NK cells can be induced in the spleen and liver by glucocorticoid (57), and anti-PD-1 blockade can induce cytokine production, such as IFN- $\gamma$, which may boost NK cells indirectly (34).

Four ongoing clinical trials are evaluating the combined effect of infused NK cells and anti-CTLA-4, PD-1, or PD-L1. They are induced pluripotent stem cell (iPSC)-derived NK cells combined with nivolumab or pembrolizumab (NCT03841110), cytokine-induced memory-like NK cells and ipilimumab (NCT 04290546), unmodified allogeneic NK cells and pembrolizumab (NCT03937895), and autologous NK cells combined with avelumab or pembrolizumab (NCT03941262).

\section{TIM-3, CEACAM1, TIGIT, and LAG-3}

TIM-3, whose cognate ligands are galectin-9 (Gal-9), phosphatidylserine, high mobility group box 1 (HMGB1), and carcinoembryonic antigen-related cell adhesion molecule 1 (CEACAM1), does not have a classical signaling motif, but five conserved tyrosine residues (58). In particular, phosphorylated Tyr256 and Tyr263 are required for the Gal-9-mediated BAT3 release from TIM-3 and inhibitory signaling (59). Gal-9 and HMGB1 can be soluble as well as membrane-bound. TIM-3 is regarded as a marker for mature NK cells and $\mathrm{TIM}-3^{+} \mathrm{PD}-1^{+} \mathrm{NK}$ cells are considered to be functionally exhausted (60). The expression of TIM-3 is elevated on peripheral NK cells in patients with advanced gastric cancer (61) and lung adenocarcinoma (62). It is also upregulated on the tumor-infiltrated NK cells in over $70 \%$ of patients with gastrointestinal stromal tumors (63). Interestingly, PD-1 expression is not found on the TIM- $3^{+}$tumorinfiltrated NK cells. Anti-TIM3 treatment rescues TIM- $3^{+}$exhausted NK cells from patients with advanced melanoma (64). Further, TIM-3 expression levels are correlated with the stage of the disease. Several anti-TIM-3 Abs are to be tested in Phase I or II clinical trials: TSR-022 by Tesaro, LY3321367 by Eli Lilly, MGB453 by Novartis, Sym023 by Symphogen, and BGB-A425 by Beigene $(65,66)$. The antibodies are often applied in combination with anti-PD-1 or anti-LAG-3 Abs in advanced solid tumors or AML. The studies are still recruiting patients, and results will be available in a few years. However, caution is warranted as the blockade of TIM-3 leads to the reduction in NK cell-mediated cytolysis of pancreatic cancer cell lines (67). Moreover, Ab-mediated Gal-9 blocking leads to a decrease in IFN- $\gamma$ production in NK cells in response to primary AML blasts (68), thereby complicating the outcomes of TIM-3 blocking.

Interestingly, CEACAM1 is also expressed in NK cells and interacts with CEACAM5 (69). Recently, NEO-201, a monoclonal antibody (mAb) specific to the CEACAM family was demonstrated to enhance NK cytotoxicity against various human 
tumor cells through CEACAM5 on tumor cells and CEACAM1 on NK cells in vitro (70) and in vivo (71). CEACAM1-expressing NK cells produce IFN- $\gamma$ by IL-12/18 in a mouse hepatitis virus infection model and the engagement of CEACAM1 was demonstrated to decrease the production IFN- $\gamma$ (72). CEACAM1 on activated NK cells inhibits NKG2D-mediated cytolytic function and signaling (73), suggesting that CEACAM1 is an immune checkpoint receptor in NK cells, as well as a cognate ligand to TIM-3. Human CEACAM1 protein has a signaling cytoplasmic domain comprising either a long ITIMcontaining domain or a short domain devoid of ITIMs (74). CEACAM1 could have 12 alternatively spliced isoforms that lead to the generation of proteins with potentially different functions.

TIGIT and CD96 are inhibitory receptors that compete with DNAM-1 (CD226), an activating receptor, for CD155 (PVR), and CD112 (Nectin-2). CD155 is highly expressed in many types of tumor cells. TIGIT and CD96 contain the ITIM motif. TIGIT contains an ITT-like motif in addition to an ITIM motif in the cytoplasmic tail, where phosphorylation of ITT-like motif upon ligand binding plays a critical role in inhibitory signaling via the recruitment of SHIP1. Engagement of TIGIT with CD155 induces its phosphorylation through Fyn and Lck and recruits SHIP1 in T cells (58). High TIGIT expression is associated with the exhaustion of tumor-infiltrated NK cells in patients with colorectal cancer (75). The blockade of TIGIT prevents NK cell exhaustion and elicit potent anti-tumor immunity in mice (75). Combined blocking of TIGIT and PD-1 showed significant tumor clearance in mice (76). TIGIT and PD-1 are often coexpressed in tumor-infiltrated NK cells (76), but only TIGIT is associated with NK cell exhaustion (75). As PVR expression is associated with unfavorable prognosis in many solid tumors, such as colon, breast, lung, and pancreatic cancers, the "PVRTIGIT axis" has been suggested as a novel target in immune checkpoint therapy (77). Notably, tiragolumab, an anti-TIGIT $\mathrm{Ab}$ developed by Genentech, is already being evaluated in two independent Phase-III clinical trials for small cell lung cancer and non-small cell lung cancer with atezolizumab, an anti-PD-L1 Ab (66), and chemotherapy. There are two other anti-TIGIT Abs, MTIG7192A and AB154, in Phase I or II trials for various solid tumors. The role of CD96 is relatively less elucidated in NK cells.

Lymphocyte activation gene-3 (LAG-3) is structurally similar to CD4 and binds to MHC class II molecules with a higher affinity than CD4. Fibrinogen-like protein 1 (FGL1) is a recently identified ligand for LAG-3 (78). LAG-3 transduces two independent inhibitory signals through the FXXL motif in the membrane-proximal region and the C-terminal EX repeat (79); the motifs are unique among the known inhibitory receptors. It is expressed on activated NK cells, and chronic stimulation of NKG2C ${ }^{+}$NK cells can induce high expression of LAG-3 (80). A soluble form of LAG-3-Ig fusion protein, IMP321 induces human NK cells to produce IFN- $\gamma$ and TNF- $\alpha$ in vitro (81). In human trials, IMP321 induced NK cell activation as monothe- rapy in advanced renal cell carcinoma (82) and combination with paclitaxel in metastatic breast cancer (83). FGL1 blockade also potentiated anti-tumor $\mathrm{T}$ cell responses in mice (78), but that of NK cells is not yet known.

\section{CD47, CD73, AND SIGLEC FAMILY PROTEINS}

In this section, we introduce some of the emerging immune checkpoint molecules in NK cell biology. CD47 is an integrinassociated protein with a short cytoplasmic domain, interacting with thrombospondin-1 (TSP-1) and signal regulatory protein $\alpha(\mathrm{SIRP} \alpha)$, an inhibitory transmembrane protein. CD47 regulates NK cell homeostasis and immune responses to lymphocytic choriomeningitis virus infection (84) and NK cell recruitment and activation in the tumor microenvironment in mice (85). CD47 is quite ubiquitously expressed. Elevated CD47 expression is associated with reduced survival in some cancers. Cord blood cell-derived CD16 ${ }^{+}$NK cells respond well to anti-CD47 Ab-treated T and B-ALL cell lines with an approximately $10 \%$ increase in cytotoxicity (86). CD47 blockade with trastuzumab (anti-HER-2 mAb) augmented anti-tumor efficacy, but the effect appears to be due to increased phagocytosis, rather than ADCC (87).

CD73, ecto-5'-nucleotidase, is probably the latest addition to immune checkpoint molecules in NK cells. The expression of CD73 is virtually absent in circulating human and mouse NK cells in healthy individuals, but tumor-infiltrated NK cells express substantial CD73 (88). It defines regulatory NK cells in the tumor environment in patients with breast cancer and sarcoma (89). $\mathrm{CD}^{+}{ }^{+} \mathrm{NK}$ cells in the tumor microenvironment express LAG-3, VISTA, PD-1, and PD-L1. NK cells transport CD73 upon engagement of $4-1 \mathrm{BB}$ on tumor cells, to express IL-10 via STAT3 activation (89). CD73 is suggested as a correlative factor of patient survival and NK cell infiltration in glioblastoma (90) and mediates immunometabolic dysfunction of NK cells under hypoxic conditions in solid tumors (91). Targeting CD73 has also been shown to suppress tumorigenesis. A first-in-class therapeutic anti-CD73 mAb, MEDI9447, is currently being evaluated in Phase I clinical trials in cancer patients (88).

Among sialic acid-binding immunoglobulin-like lectins (Siglecs), Siglec7 and Siglec9 are expressed in NK cells. Sialic acids, cognate ligands of Siglecs are 9-carbon-backbone monosaccharides, which are the glycan residues of glycoproteins and glycolipids. The cytoplasmic domains of Siglec7 and Siglec9 contain an ITIM and an ITIM-like motif (92). Siglec7 and Siglec9 share structural similarity and functionality but have different roles in virus infection and tumors. Siglec7 is expressed on mature or more cytotoxic NK cells and can reduce NK cytotoxicity. Sialic acid-containing glycan has been reported to protect tumor cells from NK cells through Siglec7 (93). Hypersialylated tumor cells can bind to Siglec9, and Siglec ${ }^{+}$NK cells express higher levels of KIRs and LIR-1. Siglec7 interacts with gangliosides, while Siglec9 interacts with mucins (92). Importantly, the desi- 
alylation of tumor cells by neuraminidases enhanced NK cytotoxicity and cytokine production (94), thereby implying novel therapeutic approaches. Siglec3 (CD33) is just recently identified as an inhibitory receptor on NK cells (95). Siglec3 inhibits cytotoxicity triggered by NKG2D via Vav1 dephosphorylation, but not by NKp46 (95).

\section{CHIMERIC ANTIGEN RECEPTORS}

\section{The potential advantage of CAR-NK cells over CAR-T cells} The majority of CAR-T cell therapies, including Kymriah ${ }^{\circledR}$ and Yescarta ${ }^{\mathbb{R}}$, use autologous $T$ cells collected from cancer patients. However, the use of autologous T cells has well-known disadvantages, including a complex manufacturing process and a low quantity of patient cells (96). Furthermore, T cell dysfunction can occur in patients who have received previous treatment with chemotherapy and/or certain other medications (97). To overcome these limitations, gene-editing tools to knockout T-cell receptors (TCRs) and human leukocyte antigen (HLA) have been employed for the generation of allogeneic CAR-T cells. These tools apply to non-HLA matched patients by reducing the potential risk of graft versus host disease (GVHD) (98-100). However, highly gene-edited cells come with unknown risks.

CAR-NK cell therapies traverse several of the limitations of CAR-T cell therapies. First, NK cells can recognize and kill tumors without HLA matching or prior antigen-sensitization (101). The transfer of allogeneic NK cells has even been shown to mediate graft-versus-tumor (GvT) responses without GvHD (102). Subsequently, NK cells can be obtained from several different sources including peripheral blood, umbilical cord blood, embryonic stem cells, and induced pluripotent stem cells (iPSCs) (103-105).

In addition, NK cell lines such as NK-92 can be utilized as allogeneic off-the-shelf CAR-expressing cell products. In contrast to primary NK cells, CAR-expressing NK-92 cells can be manufactured from a functionally and molecularly characterized single-cell clone under good manufacturing practice-compliant conditions (106). The CRISPR-Cas9 genome editing technology may allow for site-specific integration of the CAR, thereby mitigating the risk of any dysfunction in the NK-92-CAR cells. Additionally, NK-92 cells require irradiation before infusion into patients to avoid potential malignant expansion. Nonetheless, repeated infusion of irradiated CAR-NK92 cells can maintain the efficacy of CAR-NK therapy depending on the dose and frequency.

A major safety concern with CAR T-cell therapy is cytokine release syndrome (CRS). Aberrant activation of CAR T cells can lead to massive production of inflammatory cytokines including IL-6 (107). Several clinical trials have demonstrated that the adoptive transfer therapy of allogeneic CAR-NK cells does not cause severe side effects (108). CAR-NK cells may be potentially safer than CAR-T cells because of their shorter lifespan after infusion (109). There exists little clinical evidence for the comparison of the side effects of CAR-T and CAR-NK cells (110). However, according to the clinical trial of CAR-NK cell therapy at the University of Texas MD Anderson Cancer Center, the treatment of CAR-NK cells derived from cord blood showed complete remission in 7 of the 11 patients (4 with non-Hodgkin's lymphoma and 3 with chronic lymphocytic leukemia) without CRS, neurotoxicity, or GVHD, which are all potential side effects of CAR-T therapy (111).

Antigen escape is a major obstacle for effective CAR-T therapy. The immune pressure by CAR-T cells results in the outgrowth of antigen loss variants. In hematologic malignancies, CD19 loss after CAR-T therapy drives relapses $(112,113)$. CAR-NK cells could show effective antitumor activity against target antigen-negative tumors by endogenous activating receptors such as NKG2D, Nkp30, Nkp44, Nkp46, or DNAM-1 that are involved in tumor immune surveillance $(114,115)$. In addition, cytotoxic response via activating receptors including CD16 (FcyRIII) mediating antibody-dependent cellular cytotoxicity (ADCC) can synergistically enhance the antitumor activity of CAR-NK cells (116).

\section{Enhancing the anti-tumor activity of CAR-NK cells}

CARs comprise a signal peptide, a single-chain variable fragment (scFv), hinge region, transmembrane region, and intracellular domains. The composition of conventional CARs is as follows: a CD4, CD8, or IgG hinge; a CD3 $\xi$, CD4, CD8, or CD28 transmembrane domain; a 4-1BB or CD28 costimulatory domain; and a $\mathrm{CD} 3 \xi$ activation domain $(117,118)$. Herein, we describe the current efforts to optimize the clinical outcome of CAR-NK therapies for each domain.

Antigen recognition domain: The single-chain variable fragment (scFv) is an extracellular component of a CAR and confers antigen specificity. scFv is derived from the variable regions of the heavy chain and light chain of antibodies. Since the main function of scFv is antigen binding, the proper design of scFv against tumor antigens is required for better clinical outcomes. Typically, therapeutic antibodies with high-affinity binding to a specific antigen are preferred for predicted responses with minimal side effects. Although designing an scFv for a CAR is dependent on mAbs specific to the tumor-associated antigen, optimizing CAR scFv sequences for the best clinical outcome is still under discussion. Chmielewski et al. generated T cells expressing chimeric TCR pools against human epidermal growth factor receptor 2 (ERBB2, HER2) with a Kd ranging from $3.2 \times$ $10^{-7}$ to $1.5 \times 10^{-11} \mathrm{M}$. Researchers demonstrated that a higher affinity receptor did not correlate with the potency of $\mathrm{T}$ cell activation. Moreover, T cells with high-affinity receptors could induce an immune response to normal tissue expressing low antigen levels (119). Morgan et al. reported a clinical case study on the administration of CAR-T cells-derived from the FDA-approved therapeutic mAb, trastuzumab (Herceptin), that targets HER2, a tumor-associated antigen used to treat metastatic colon cancer. The patient presented side effects resulting from a dramatic pulmonary infiltration of CAR-T cells by the recognition of low expression levels of HER2 in normal lung 
epithelial cells and died 5 days after administration (120). Phase I clinical trial of NK-92/5.28.z (CAR-NK-92 cells targeting HER2 with trastuzumab scFv) is presently ongoing in patients with recurrent HER2-positive glioblastoma (CAR2BRAIN, NCT03383978, clinicaltrials.gov). So far, no remarkable adverse effects have been observed, but more detailed clinical signs should be confirmed in dose-escalating studies (121).

The design of an scFv for CAR-NK therapies is still in its early stages. Because CAR-NK cells are generally more tolerant than CAR-T cells, we would select the one with the strongest affinity. Moreover, NK-92-CAR cells have to be irradiated before infusion, this process can decrease the potency of NK-92-CAR cells. Currently, the sequences for therapeutic mAbs are being adapted for scFv design, but we will consider all possible factors including biochemical (affinity), the transmission of activation signaling in the CAR-NK cells, compatibilities with the cytoplasmic domain of the CAR, and side effects observed in clinical trials, to obtain the best clinical outcome.

Spacer, transmembrane, and costimulatory domains: Since NK cells express $\mathrm{CD} 3 z$ for transmitting activation signaling similarly to T cells (122), the intracellular domain of CD3z is generally used for CAR designs for NK cells. The first generation of CARs generally contained only the CD3z domain for signal transduction. However, due to CD3z's weak potency, costimulatory domains (e.g., CD28 or $4-1 \mathrm{BB}$, or both) were added to the cytoplasmic region of second/third generation CARs (123). A previous study showed that incorporation of DNAX-activation protein 12 (DAP12) instead of the CD3z activation domain allowed the lysis of KIR/HLA-matched prostate stem cell antigen (PSCA)-positive tumor cell lines and was considered suitable for CAR-NK therapy against solid tumors (124). The CD28 and 4-1BB costimulatory domains of thirdgeneration CARs of iPSC-derived NK cells can be replaced with the combination of an NKG2D transmembrane and 2B4 cytoplasmic domain that can induce synergistic activation of NK cells with enhanced antitumor activity of iPSC-CAR NK cells (104). These studies highlighted that the selection of optimal transmembrane and cytoplasmic signaling domains of a CAR unique to NK cells can improve the antitumor activity of CAR-NK cells in a manner different from CAR-T cells.

In addition, distinct hinge domains alter the performance of CAR-T cell therapies. The extracellular spacer has been reported to affect the accessibility of a CAR to approach the target epitope and decides the cell-cell distance depending on the length (125). Moreover, the selection of an optimal hinge region contributes to CAR dimerization and performance. This may be due to structural interactions as well as the flexibility of the CAR $(126,127)$. Further, the incorporation of 4-1BB costimulatory domains has been demonstrated to ameliorate the exhaustion of $\mathrm{T}$ cells caused by CAR-mediated antigenindependent tonic signaling thereby leading to functional differences (128). The difference between $C D 28 / C D 3 \xi$ and $4-1 \mathrm{BB} / \mathrm{CD} 3 \xi$ is associated with kinetics and signal strength (129).
Fourth-generation CARs: Fourth-generation CAR-T cells are engineered to secrete transgenic cytokines. Cytokine-mediated "signal 3" is known to be important for T or NK cell activation and persistence. These CARs, armed with cytokines, were validated to enhance antitumor activities in several studies on $T$ cells. The persistence of CAR-expressing effector cells is associated with improved clinical outcomes $(127,130)$. Adoptively transferred NK cells have limited persistence in vivo, thereby potentially limiting the efficacy of CAR-NK cells. Genetic engineering of CAR-NK cells to express IL-15, which is associated with increased proliferation and survival of NK cells, enhanced the persistence and efficacy of CAR-NK cells $(103,131)$. Ex-vivo NK cells cultured with IL-15 and a pharmacological inhibitor of the glycogen synthase kinase 3 (GSK3) enhanced CD57 upregulation, promoted late-stage maturation, and improved the antitumor activity of the NK cells (132).

Several interesting studies focusing on signal 3 were conducted in CAR-T cells. Kagoya et al. developed CARs with truncated IL-2Rbeta and STAT3 binding YXXQ motif in addition to the CD28-CD3z cytoplasmic domain, thereby resulting in enhanced antitumor activity (133). Chmielewski et al. developed TRUCKs (T cells redirected for antigen-unrestricted cytokine-initiated killing), an NFAT-based cytokine expression system to increase the cytotoxicity of CAR cells $(134,135)$. Hurton et al. engineered CARs with IL-15 fused to the IL-15Ralpha via a flexible linker (136). However, these mechanistic studies are based on T cells and the conventional CAR structure. The biological mechanisms behind CAR signaling when using different CAR constructs or different cell types such as NK cells are not well understood. It is hypothesized that the exploration of various CARs and activation pathways based on NK cells improves CAR-NK therapy by determining optimal constructs and methodological complications such as cell sources, ex vivo culture, infusion dose, and frequency. Next, we will describe current attempts conducted in industries for CAR-NK anti-cancer therapy employing various new technologies.

\section{CAR-NK DEVELOPMENT IN INDUSTRY: CURRENT STATUS}

Here, we summarize the current status of CAR-NK developments in the biotech and pharmaceutical industries (Fig. 2). Bellicum Pharmaceuticals (Houston, TX) is developing the novel technology GoCAR ${ }^{\mathrm{TM}} \mathrm{NK}$ cell therapy by introducing both rimiducid-inducible iMC (MyD88-CD40 dimerization) for NK cell activation and proliferation along with rapamycin-inducible iRC9 (Caspase-9) for safety into NK cells. Anti-CD123 and anti-HER2 CAR-NK cells with iMC and autocrine IL-15 showed enhanced persistence and anti-tumor activity in in vivo CD123+ AML and HER2 + solid tumor models, respectively (137). Bellicum has announced that GoCAR ${ }^{\mathrm{TM}} \mathrm{NK}$ cells targeting BCMA are in preclinical development for treating multiple myeloma.

Fate Therapeutics Inc. is developing NKCAR-iPSC-NK cells that target the CD19 antigen, FT596, armed with a high-affi- 


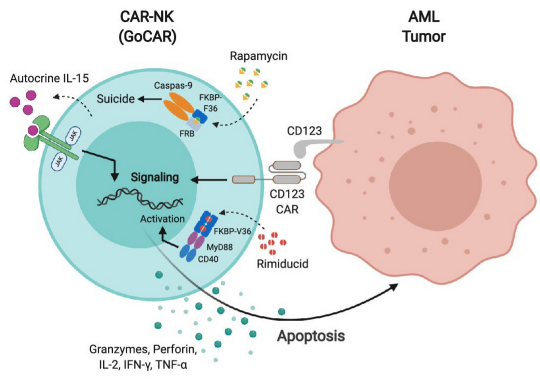

C

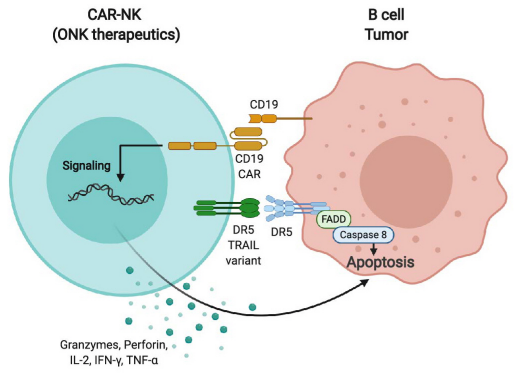

E

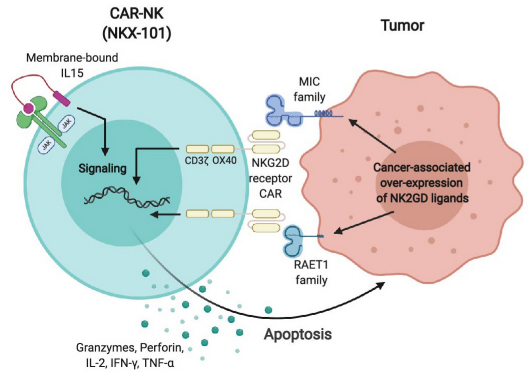

B

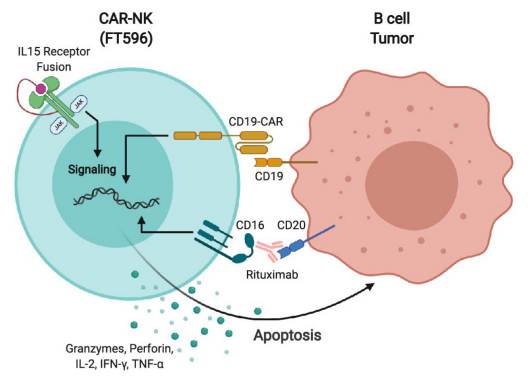

D

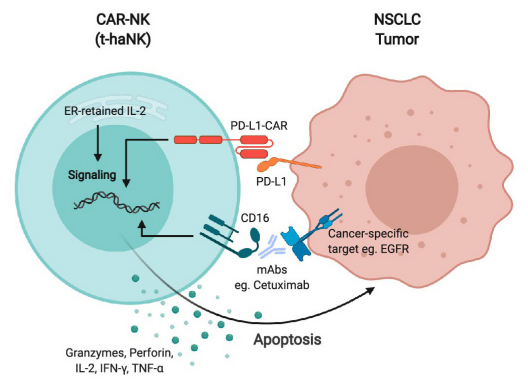

Fig. 2. Development of CAR-NK cell therapies in the industry. (A) GoCAR-NK utilizes Rimiducid and Rapamycin for inducible activation and suicide signaling, respectively. (B) FT596, combined with Rituximab, can target both CD19 and CD20 with CD16 Fc receptor in $B$ cell malignancy. IL-15 receptor fusion protein with a flexible IL-15 is introduced for further NK cell activation. (C) ONK therapeutics use TRAIL signaling for maximizing tumor cell apoptosis. A high-affinity variant of TRAIL is recognized by the DR5 TRAIL receptor, thereby resulting in activation of FADDCaspase8 signaling in a target tumor cell. (D) t-haNK is a versatile platform targeting tumors with a combination of CAR and therapeutic antibody. In this figure, we illustrate an example of NSCLC which expresses a high level of PD-L1 and EGFR. ER-retained IL-2 also drives NK cell activation and persistence. (E) NKX-101 uses NKG2D-CAR for tumor antigen recognition, membrane-bound IL15 for further activation as well. NKG2D ligands (MIC and RAET1 families) are highly expressed in various tumor cells. nity, non-cleavable CD16 FCR and a novel IL-15 receptor fusion. The high-affinity CD16 receptor allowed the CAR-NK cells to overcome resistance induced by CD19 antigen loss in combination with rituximab (CD20 therapeutic mAb) in a Raji CD19-CD20 + lymphoma model [ASH 2018, 2019]. FT596 is now under Phase I clinical trial for patients with B cell lymphoma and chronic lymphocytic leukemia [NCT04245722].

Avectas and ONK therapeutics are developing a CAR-NK cell therapy by incorporating DR5 TRAIL variants to maximize cytotoxicity in various tumors including CD19 targeting B-cell lymphomas (patent US 10,034,925). The DR5 TRAIL variant showed a maximum of 1,000-fold or greater binding affinity compared to other variants, thereby resulting in TRAIL receptormediated apoptosis in target tumor cells.

GEMoaB Monoclonals $\mathrm{GmbH}$ is developing a universal CAR platform (Uni-CAR) which uses a switchable turn-on/off mechanism by binding with cancer-specific targeting modules (TM) (138). Uni-CAR NK-92 cells are redirected and activated by scFv- and IgG4-based TM specific for tumor antigen GD2, thereby resulting in anti-tumor activity in GD2-expressing solid tumor mouse models. In vivo pharmacokinetic analysis showed rapid elimination of scFv-based TM with a half-life of $1.6 \mathrm{~h}$.

NantKwest Inc. is developing t-haNK cells that target the PD-L1 in non-small cell lung cancer. The t-haNK cells express an anti-PD-L1 CAR, a high-affinity CD16, and an endoplasmic reticulum retained IL-2 (139). T-haNK is now under Phase I clinical trial for patients with locally advanced or metastatic solid tumors (NCT04050709).

Nkarta Therapeutics Inc. is developing NKX-101: CAR-NK cells consisting of NKG2D receptors in the extracellular domain, 
Boosting NK cells based on ICRs and CARs

Nayoung Kim, et al.

Table 2. Clinical trials with CAR-NK cells

\begin{tabular}{|c|c|c|c|c|c|c|}
\hline $\begin{array}{l}\text { Clinical } \\
\text { trials.gov } \\
\text { identifier }\end{array}$ & Title or CAR-NK strategy & Target disease & $\begin{array}{l}\text { Source of NK } \\
\text { cell }\end{array}$ & Sponsor & Start date & Status \\
\hline NCT03692767 & Anti-CD22 CAR NK & $\begin{array}{l}\text { Relapsed and } \\
\text { refractory B cell } \\
\text { lymphoma }\end{array}$ & & $\begin{array}{l}\text { Allife Medical Science and } \\
\text { Technology Co., Ltd. }\end{array}$ & March 2019 & $\begin{array}{l}\text { Not yet } \\
\text { recruiting }\end{array}$ \\
\hline NCT03690310 & Anti-CD19 CAR NK & $\begin{array}{l}\text { Relapsed and } \\
\text { refractory B cell } \\
\text { lymphoma }\end{array}$ & & $\begin{array}{l}\text { Allife Medical Science and } \\
\text { Technology Co., Ltd. }\end{array}$ & March 2019 & $\begin{array}{l}\text { Not yet } \\
\text { recruiting }\end{array}$ \\
\hline NCT03692637 & Anti-mesothelin CAR NK & $\begin{array}{l}\text { Epithelial } \\
\text { ovarian cancer }\end{array}$ & & $\begin{array}{l}\text { Allife Medical Science and } \\
\text { Technology Co., Ltd. }\end{array}$ & March 2019 & $\begin{array}{l}\text { Not yet } \\
\text { recruiting }\end{array}$ \\
\hline NCT03415100 & $\begin{array}{l}\text { NKG2D-ligand targeted } \\
\text { CAR-NK }\end{array}$ & $\begin{array}{l}\text { Metastatic } \\
\text { solid tumors }\end{array}$ & & $\begin{array}{l}\text { The Third Affiliated } \\
\text { Hospital of Guangzhou } \\
\text { Medical University }\end{array}$ & January 2, 2018 & Unknown \\
\hline NCT04324996 & NKG2D-ACE2 CAR-NK & COVID-19 & Cord blood & $\begin{array}{l}\text { Chongqing Public Health } \\
\text { Medical Center }\end{array}$ & February 21, 2020 & Recruiting \\
\hline NCT03692663 & Anti-PSMA CAR NK & $\begin{array}{l}\text { Castration-resistant } \\
\text { prostate cancer }\end{array}$ & & $\begin{array}{l}\text { Allife Medical Science and } \\
\text { Technology Co., Ltd. }\end{array}$ & December 2018 & $\begin{array}{l}\text { Not yet } \\
\text { recruiting }\end{array}$ \\
\hline NCT03940820 & ROBO1 specific CAR-NK & Solid tumors & & $\begin{array}{l}\text { Asclepius Technology } \\
\text { Company Group (Suzhou) } \\
\text { Co., Ltd. }\end{array}$ & May 2019 & Recruiting \\
\hline NCT03940833 & BCMA CAR-NK 92 cells & $\begin{array}{l}\text { Relapse/refractory } \\
\text { multiple } \\
\text { myeloma }\end{array}$ & NK-92 cell line & $\begin{array}{l}\text { Asclepius Technology } \\
\text { Company Group (Suzhou) } \\
\text { Co., Ltd. }\end{array}$ & May 2019 & Recruiting \\
\hline NCT03824964 & Anti-CD19/CD22 CAR NK & $\begin{array}{l}\text { Relapsed and } \\
\text { refractory B cell } \\
\text { lymphoma }\end{array}$ & & $\begin{array}{l}\text { Allife Medical Science and } \\
\text { Technology Co., Ltd. }\end{array}$ & February 1, 2019 & $\begin{array}{l}\text { Not yet } \\
\text { recruiting }\end{array}$ \\
\hline NCT02944162 & Anti-CD33 CAR-NK & $\begin{array}{l}\text { Relapsed/refractory } \\
\text { CD33 + AML }\end{array}$ & NK-92 cell line & $\begin{array}{l}\text { PersonGen BioTherapeutics } \\
\text { (Suzhou) Co., Ltd. }\end{array}$ & October 2016 & Unknown \\
\hline NCT02892695 & $\begin{array}{l}\text { PCAR-119 bridge } \\
\text { immunotherapy before } \\
\text { stem cell transplant } \\
\text { (anti-CD19 CAR-NK) }\end{array}$ & $\begin{array}{l}\text { CD19 positive } \\
\text { leukemia and } \\
\text { lymphoma }\end{array}$ & NK-92 cell line & $\begin{array}{l}\text { PersonGen BioTherapeutics } \\
\text { (Suzhou) Co., Ltd. }\end{array}$ & September 2016 & Unknown \\
\hline NCT03941457 & $\begin{array}{l}\text { ROBO1 specific } \\
\text { BiCAR-NK }\end{array}$ & Pancreatic cancer & & $\begin{array}{l}\text { Asclepius Technology } \\
\text { Company Group (Suzhou) } \\
\text { Co., Ltd. }\end{array}$ & May 2019 & Recruiting \\
\hline NCT03931720 & $\begin{array}{l}\text { ROBO1 Specific } \\
\text { BiCAR-NK/T }\end{array}$ & Malignant tumor & & $\begin{array}{l}\text { Asclepius Technology } \\
\text { Company Group (Suzhou) } \\
\text { Co., Ltd. }\end{array}$ & May 2019 & Recruiting \\
\hline NCT03056339 & $\begin{array}{l}\text { Umbilical \& cord blood } \\
\text { (CB) derived } \\
\text { CAR-engineered NK; } \\
\text { (iC9/CAR.19/IL15- } \\
\text { transduced CB-NK) }\end{array}$ & $\begin{array}{l}\text { B lymphoid } \\
\text { malignancies }\end{array}$ & Cord blood & $\begin{array}{l}\text { M.D. Anderson Cancer } \\
\text { Center }\end{array}$ & June 21, 2017 & Recruiting \\
\hline NCT04245722 & $\begin{array}{l}\text { FT596 as } \\
\text { a monotherapy and in } \\
\text { combination with } \\
\text { anti-CD20 monoclonal } \\
\text { antibodies }\end{array}$ & $\begin{array}{l}\text { B cell lymphoma, } \\
\text { chronic } \\
\text { lymphocytic } \\
\text { leukemia }\end{array}$ & iPSC & Fate Therapeutics & March 19, 2020 & Recruiting \\
\hline NCT04050709 & $\begin{array}{l}\text { QUILT 3.064: } \\
\text { PD-L1 t-haNK }\end{array}$ & $\begin{array}{l}\text { Locally advanced } \\
\text { or metastatic } \\
\text { solid cancers }\end{array}$ & NK-92 cell line & NantKwest, Inc. & July 18,2019 & $\begin{array}{l}\text { Active, } \\
\text { not } \\
\text { recruiting }\end{array}$ \\
\hline NCT03383978 & $\begin{array}{l}\text { Intracranial injection of } \\
\text { NK-92/5.28.z } \\
\text { (CAR2BRAIN) }\end{array}$ & $\begin{array}{l}\text { Recurrent } \\
\text { HER2-positive } \\
\text { glioblastoma }\end{array}$ & NK-92 cell line & $\begin{array}{l}\text { Johann Wolfgang Goethe } \\
\text { University Hospital }\end{array}$ & December 1, 2017 & Recruiting \\
\hline
\end{tabular}


OX40-CD3z in the costimulatory domain, and membrane-bound IL-15. The NKG2D receptor binds to eight NKG2D ligands that are upregulated in a range of leukemic and solid tumors. CAR-NK cells targeting these ligands showed antitumor activity in a murine model of osteosarcoma (140). NKX-101 showed in vitro anti-tumor activity and increased cell delivery in an in vivo model of colorectal cancer liver metastasis (ASCO 2020).

Takeda, under license from MD Anderson Cancer Center, is developing TAK-007: cord blood-NK cells that are transduced to express CAR targeting CD19 with a CD28 costimulatory domain, IL-15, and an inducible caspase 9 suicide gene. In a recent small-scale clinical trial, TAK-007 showed a response rate of $73 \%$ for patients with relapsed or refractory CD19positive cancers (111). Some additional CAR-NK cell therapies are under development targeting several tumor-associated antigens including MUC1 for solid tumors (PersonGen Biomedicine Co. Ltd), CD38 for AML (Celularity Inc), EGFRvIll for PD-L1 positive solid tumors (PharmAbcine), CD7 for T cell leukemia (Gracell Biotechnology Ltd), GPC-3 for hepatocellular carcinoma (Baylor College of Medicine, Kuur therapeutics), and CSPG4 for triple-negative breast cancer (Baylor College of Medicine). The ongoing clinical trials with NK-CARs are presented in Table 2.

\section{CONCLUSIONS AND PERSPECTIVES}

NK cells have the potential to kill a broad spectrum of tumor cells without mutational burden and neoantigen presentation. This property of MHC-unrestricted tumor lysis by NK cells without the risk of GVHD, which is unique among immune effector cells, has positioned NK cells as key components in the arsenal of cancer therapeutics. Recent studies on cancer therapies using NK cells have demonstrated favorable clinical efficacies in hematologic malignancies, but limited success in solid tumors. This may be attributed to the limited capacity of NK cells to infiltrate tumors, persist in vivo, or resist in the immunosuppressive tumor microenvironment. Thus, rational strategies for improving NK cell-based therapy have been developed to overcome the existing challenges. These include the blockade of immune checkpoint receptors to rescue dysfunctional NK cells and the incorporation of tumor-directed CAR to augment anti-tumor NK cell specificity and activity.

Since the early studies on KIRs, numerous immune checkpoint receptors revealed to be functionally quintessential in NK cell function. Immune checkpoint blockades that can stimulate NK cells have tremendous potential in cancer therapy. They could not only stimulate NK cells but also T cells in direct and indirect ways, particularly under the situation of blocking immune checkpoint receptors that are expressed on both the cell types. In addition, combination therapies with immune checkpoint blockade and chemotherapy or CAR-T/NK therapy could become a part of standard therapeutic regimens in the near future.

Despite challenges in the genetic manipulation of NK cells,
CAR-NK cells have received increasing attention as next-generation therapeutics against refractory malignancies including solid tumors. In addition to the redirected specificity, they hold promise with "off-the-shelf" clinical utility and low toxicity usually not causing immune-related adverse events. Moreover, further engineering of CAR-NK cells with on-board cytokines (e.g., IL-15) that leads to enhanced in vivo persistence and resistance to immunosuppression has paved the way for new therapeutic options to improve clinical efficacy $(103,141)$. These observations, along with several reliable protocols for GMP-grade large scale expansion of NK cells, will render NK cell-based therapy a viable modality to treat refractory cancers, possibly in rational and optimal combination with other therapies.

\section{ACKNOWLEDGEMENTS}

This study was supported by a grant from the National Research Foundation of Korea (2019R1A2C2006475) and an MRC grant (2018R1A5A2020732) funded by the Korean government (MSIT).

\section{CONFLICTS OF INTEREST}

The authors have no conflicting interests.

\section{REFERENCES}

1. Larkin J, Chiarion-Sileni V, Gonzalez R et al (2015) Combined Nivolumab and Ipilimumab or monotherapy in untreated melanoma. N Engl J Med 373, 23-34

2. Ishida Y, Agata Y, Shibahara K and Honjo T (1992) Induced expression of PD-1, a novel member of the immunoglobulin gene superfamily, upon programmed cell death. EMBO J 11, 3887-3895

3. Selvakumar A, Mohanraj BK, Eddy RL, Shows TB, White $\mathrm{PC}$ and Dupont B (1992) Genomic organization and chromosomal location of the human gene encoding the B-lymphocyte activation antigen B7. Immunogenetics $36,175-181$

4. Karre $\mathrm{K}$, Ljunggren $\mathrm{HG}$, Piontek $\mathrm{G}$ and Kiessling $\mathrm{R}$ (1986) Selective rejection of $\mathrm{H}$-2-deficient lymphoma variants suggests alternative immune defence strategy. Nature 319, 675-678

5. Kim S, Poursine-Laurent J, Truscott SM et al (2005) Licensing of natural killer cells by host major histocompatibility complex class I molecules. Nature 436, 709-713

6. Kim S, Sunwoo JB, Yang L et al (2008) HLA alleles determine differences in human natural killer cell responsiveness and potency. Proc Natl Acad Sci U S A 105, 3053-3058

7. Djaoud Z and Parham P (2020) HLAs, TCRs, and KIRs, a triumvirate of human cell-mediated immunity. Annu Rev Biochem 89, 717-739

8. Saunders PM, Vivian JP, O'Connor GM et al (2015) A bird's eye view of NK cell receptor interactions with their MHC class I ligands. Immunol Rev 267, 148-166 
9. Benson DM, Jr., Hofmeister CC, Padmanabhan $\mathrm{S}$ et al (2012) A phase 1 trial of the anti-KIR antibody IPH2101 in patients with relapsed/refractory multiple myeloma. Blood 120, 4324-4333

10. Vey N, Bourhis JH, Boissel $\mathrm{N}$ et al (2012) A phase 1 trial of the anti-inhibitory KIR mAb IPH2101 for AML in complete remission. Blood 120, 4317-4323

11. Carlsten M, Korde N, Kotecha R et al (2016) Checkpoint inhibition of KIR2D with the monoclonal antibody IPH2101 induces contraction and hyporesponsiveness of NK cells in patients with myeloma. Clin Cancer Res 22, 5211-5222

12. Benson DM Jr, Cohen AD, Jagannath $S$ et al (2015) A phase I trial of the anti-KIR antibody IPH2101 and lenalidomide in patients with relapsed/refractory multiple myeloma. Clin Cancer Res 21, 4055-4061

13. Kohrt HE, Thielens A, Marabelle A et al (2014) Anti-KIR antibody enhancement of anti-lymphoma activity of natural killer cells as monotherapy and in combination with anti-CD20 antibodies. Blood 123, 678-686

14. Yalniz FF, Daver N, Rezvani K et al (2018) A pilot trial of Lirilumab with or without Azacitidine for patients with myelodysplastic syndrome. Clin Lymphoma Myeloma Leuk 18, 658-663 e652

15. Binyamin L, Alpaugh RK, Hughes TL, Lutz CT, Campbell KS and Weiner LM (2008) Blocking NK cell inhibitory self-recognition promotes antibody-dependent cellular cytotoxicity in a model of anti-lymphoma therapy. J Immunol 180, 6392-6401

16. Bagot M, Porcu $P$, Marie-Cardine A et al (2019) IPH4102, a first-in-class anti-KIR3DL2 monoclonal antibody, in patients with relapsed or refractory cutaneous T-cell lymphoma: an international, first-in-human, openlabel, phase 1 trial. Lancet Oncol 20, 1160-1170

17. Ewen EM, Pahl JHW, Miller M, Watzl C and Cerwenka A (2018) KIR downregulation by IL-12/15/18 unleashes human NK cells from KIR/HLA-I inhibition and enhances killing of tumor cells. Eur J Immunol 48, 355-365

18. Shiroishi M, Tsumoto K, Amano K et al (2003) Human inhibitory receptors Ig-like transcript 2 (ILT2) and ILT4 compete with CD8 for MHC class I binding and bind preferentially to HLA-G. Proc Natl Acad Sci U S A 100, 8856-8861

19. Khan M, Arooj S and Wang $H$ (2020) NK cell-based immune checkpoint inhibition. Front Immunol 11, 167

20. Scarabel L, Garziera M, Fortuna S, Asaro F, Toffoli G and Geremia S (2020) Soluble HLA-G expression levels and HLA-G/irinotecan association in metastatic colorectal cancer treated with irinotecan-based strategy. Sci Rep 10,8773

21. Bertol BC, de Araujo JNG, Sadissou IA et al (2020) Plasma levels of soluble HLA-G and cytokines in papillary thyroid carcinoma before and after thyroidectomy. Int J Clin Pract 74, e13585

22. Heidenreich $\mathrm{S}, \mathrm{Zu}$ Eulenburg $\mathrm{C}$, Hildebrandt $\mathrm{Y}$ et al (2012) Impact of the NK cell receptor LIR-1 (ILT-2/ CD85j/LILRB1) on cytotoxicity against multiple myeloma. Clin Dev Immunol 2012, 652130

23. Godal R, Bachanova V, Gleason M et al (2010) Natural killer cell killing of acute myelogenous leukemia and acute lymphoblastic leukemia blasts by killer cell immunoglobulin-like receptor-negative natural killer cells after NKG2A and LIR-1 blockade. Biol Blood Marrow Transplant 16, 612-621

24. Ho GT, Celik AA, Huyton T et al (2020) NKG2A/CD94 is a new immune receptor for HLA-G and distinguishes amino acid differences in the HLA-G heavy chain. Int J Mol Sci 21, 4362

25. Burshtyn DN, Scharenberg AM, Wagtmann $\mathrm{N}$ et al (1996) Recruitment of tyrosine phosphatase HCP by the killer cell inhibitor receptor. Immunity 4, 77-85

26. Olcese L, Lang P, Vely F et al (1996) Human and mouse killer-cell inhibitory receptors recruit PTP1C and PTP1D protein tyrosine phosphatases. J Immunol 156, 4531-4534

27. Stebbins CC, Watzl C, Billadeau DD, Leibson PJ, Burshtyn DN and Long EO (2003) Vav1 dephosphorylation by the tyrosine phosphatase SHP-1 as a mechanism for inhibition of cellular cytotoxicity. Mol Cell Biol 23, 6291-6299

28. Liu D, Peterson ME and Long EO (2012) The adaptor protein Crk controls activation and inhibition of natural killer cells. Immunity 36, 600-611

29. Long EO, Sik Kim H, Liu D, Peterson ME and Rajagopalan S (2013) Controlling natural killer cell responses: integration of signals for activation and inhibition. Annu Rev Immunol 31, 227-258

30. Levy EM, Bianchini M, Von Euw EM et al (2008) Human leukocyte antigen-E protein is overexpressed in primary human colorectal cancer. Int J Oncol 32, 633-641

31. Gooden M, Lampen M, Jordanova ES et al (2011) HLA-E expression by gynecological cancers restrains tumor-infiltrating CD8(+) T lymphocytes. Proc Natl Acad Sci U S A 108, 10656-10661

32. Della Chiesa M, Pesce S, Muccio L et al (2016) Features of memory-like and PD-1(+) human NK cell subsets. Front Immunol 7, 351

33. McWilliams EM, Mele JM, Cheney C et al (2016) Therapeutic CD94/NKG2A blockade improves natural killer cell dysfunction in chronic lymphocytic leukemia. Oncoimmunology 5, e1226720

34. Chiossone L, Vienne M, Kerdiles YM and Vivier E (2017) Natural killer cell immunotherapies against cancer: checkpoint inhibitors and more. Semin Immunol 31, 55-63

35. Burugu S, Dancsok AR and Nielsen TO (2018) Emerging targets in cancer immunotherapy. Semin Cancer Biol 52, 39-52

36. Andre P, Denis C, Soulas C et al (2018) Anti-NKG2A $\mathrm{mAb}$ is a checkpoint inhibitor that promotes anti-tumor immunity by unleashing both T and NK cells. Cell 175, 1731-1743

37. van Montfoort N, Borst L, Korrer MJ et al (2018) NKG2A blockade potentiates CD8 T cell immunity induced by cancer vaccines. Cell 175, 1744-1755

38. Schildberg FA, Klein SR, Freeman GJ and Sharpe AH (2016) Coinhibitory pathways in the B7-CD28 ligandreceptor family. Immunity 44, 955-972

39. Stojanovic A, Fiegler N, Brunner-Weinzierl $M$ and Cerwenka A (2014) CTLA-4 is expressed by activated mouse NK cells and inhibits NK Cell IFN-gamma production in response to mature dendritic cells. J Immunol $192,4184-4191$ 
40. Jie HB, Schuler PJ, Lee SC et al (2015) CTLA-4(+) regulatory $T$ cells increased in Cetuximab-treated head and neck cancer patients suppress NK cell cytotoxicity and correlate with poor prognosis. Cancer Res 75, 2200-2210

41. Romano E, Kusio-Kobialka M, Foukas PG et al (2015) Ipilimumab-dependent cell-mediated cytotoxicity of regulatory $\mathrm{T}$ cells ex vivo by nonclassical monocytes in melanoma patients. Proc Natl Acad Sci U S A 112, 6140-6145

42. Simpson TR, Li F, Montalvo-Ortiz W et al (2013) Fc-dependent depletion of tumor-infiltrating regulatory $T$ cells co-defines the efficacy of anti-CTLA-4 therapy against melanoma. J Exp Med 210, 1695-1710

43. Tallerico R, Cristiani CM, Staaf E et al (2017) IL-15, TIM-3 and NK cells subsets predict responsiveness to anti-CTLA-4 treatment in melanoma patients. Oncoimmunology 6, e1261242

44. Jallad MN, Jurjus AR, Rahal EA and Abdelnoor AM (2020) Triple immunotherapy overcomes immune evasion by tumor in a melanoma mouse model. Front Oncol 10,839

45. Lang S, Vujanovic NL, Wollenberg B and Whiteside TL (1998) Absence of B7.1-CD28/CTLA-4-mediated co-stimulation in human NK cells. Eur J Immunol 28, 780-786

46. Cook CH, Chen L, Wen J et al (2009) CD28/B7mediated co-stimulation is critical for early control of murine cytomegalovirus infection. Viral Immunol 22, 91-103

47. Boussiotis VA, Chatterjee P and Li L (2014) Biochemical signaling of PD-1 on T cells and its functional implications. Cancer J 20, 265-271

48. Pesce S, Greppi M, Tabellini G et al (2017) Identification of a subset of human natural killer cells expressing high levels of programmed death 1: a phenotypic and functional characterization. J Allergy Clin Immunol $139,335-346$ e333

49. Tabellini G, Benassi M, Marcenaro E et al (2014) Primitive neuroectodermal tumor in an ovarian cystic teratoma: natural killer and neuroblastoma cell analysis. Case Rep Oncol 7, 70-78

50. Beldi-Ferchiou A, Lambert M, Dogniaux S et al (2016) PD-1 mediates functional exhaustion of activated NK cells in patients with Kaposi sarcoma. Oncotarget 7, 7296172977

51. Benson DM Jr, Bakan CE, Mishra A et al (2010) The PD-1/PD-L1 axis modulates the natural killer cell versus multiple myeloma effect: a therapeutic target for CT-011, a novel monoclonal anti-PD-1 antibody. Blood 116, 2286-2294

52. Vari F, Arpon D, Keane $C$ et al (2018) Immune evasion via PD-1/PD-L1 on NK cells and monocyte/macrophages is more prominent in Hodgkin lymphoma than DLBCL. Blood 131, 1809-1819

53. Hsu J, Hodgins JJ, Marathe $M$ et al (2018) Contribution of NK cells to immunotherapy mediated by PD-1/PD-L1 blockade. J Clin Invest 128, 4654-4668

54. Lanuza PM, Vigueras A, Olivan S et al (2018) Activated human primary NK cells efficiently kill colorectal cancer cells in 3D spheroid cultures irrespectively of the level of PD-L1 expression. Oncoimmunology 7, e1395123

55. Hwang S, Han J, Baek JS et al (2019) Cytotoxicity of human hepatic intrasinusoidal CD56(bright) natural killer cells against hepatocellular carcinoma cells. Int J Mol Sci 20, 1564

56. Judge SJ, Dunai C, Aguilar EG et al (2020) Minimal PD-1 expression in mouse and human NK cells under diverse conditions. J Clin Invest 130, 3051-3068

57. Quatrini L, Wieduwild E, Escaliere B et al (2018) Endogenous glucocorticoids control host resistance to viral infection through the tissue-specific regulation of PD-1 expression on NK cells. Nat Immunol 19, 954-962

58. Anderson AC, Joller N and Kuchroo VK (2016) Lag-3, Tim-3, and TIGIT: co-inhibitory receptors with specialized functions in immune regulation. Immunity 44, 9891004

59. Rangachari M, Zhu C, Sakuishi $K$ et al (2012) Bat3 promotes $T$ cell responses and autoimmunity by repressing Tim-3-mediated cell death and exhaustion. Nat Med 18, $1394-1400$

60. Carotta S (2016) Targeting NK cells for anticancer immunotherapy: clinical and preclinical approaches. Front Immunol 7,152

61. Wang Z, Zhu J, Gu H et al (2015) The clinical significance of abnormal Tim-3 expression on NK cells from patients with gastric cancer. Immunol Invest 44, 578-589

62. Xu L, Huang Y, Tan L et al (2015) Increased Tim-3 expression in peripheral NK cells predicts a poorer prognosis and Tim-3 blockade improves NK cell-mediated cytotoxicity in human lung adenocarcinoma. Int Immunopharmacol 29, 635-641

63. Komita H, Koido S, Hayashi K et al (2015) Expression of immune checkpoint molecules of $\mathrm{T}$ cell immunoglobulin and mucin protein 3/galectin-9 for NK cell suppression in human gastrointestinal stromal tumors. Oncol Rep 34, 2099-2105

64. Gallois A, Silva I, Osman I and Bhardwaj N (2014) Reversal of natural killer cell exhaustion by TIM-3 blockade. Oncoimmunology 3, e946365

65. Zhang C and Liu Y (2020) Targeting NK cell checkpoint receptors or molecules for cancer immunotherapy. Front Immunol 11, 1295

66. Chauhan SKS, Koehl U and Kloess S (2020) Harnessing NK cell checkpoint-modulating immunotherapies. Cancers (Basel) 12, 1807

67. Van Audenaerde JRM, De Waele J, Marcq E et al (2017) Interleukin-15 stimulates natural killer cell-mediated killing of both human pancreatic cancer and stellate cells. Oncotarget 8, 56968-56979

68. Folgiero V, Cifaldi L, Li Pira G, Goffredo BM, Vinti L and Locatelli $F$ (2015) TIM-3/Gal-9 interaction induces IFN gamma-dependent IDO1 expression in acute myeloid leukemia blast cells. J Hematol Oncol 8, 36

69. Markel G, Gruda R, Achdout $\mathrm{H}$ et al (2004) The critical role of residues $43 \mathrm{R}$ and $44 \mathrm{Q}$ of carcinoembryonic antigen cell adhesion molecules- 1 in the protection from killing by human NK cells. J Immunol 173, 3732-3739

70. Fantini M, David JM, Annunziata CM, Morelli MP, Arlen PM and Tsang KY (2020) The monoclonal antibody NEO201 enhances natural killer cell cytotoxicity against tumor cells through blockade of the inhibitory CEACAM5/ 
CEACAM1 immune checkpoint pathway. Cancer Biother Radiopharm 35, 190-198

71. Zeligs KP, Morelli MP, David JM et al (2020) Evaluation of the anti-tumor activity of the humanized monoclonal antibody NEO-201 in preclinical models of ovarian cancer. Front Oncol 10, 805

72. Jacques A, Bleau C, Turbide C, Beauchemin N and Lamontagne $L$ (2009) A synergistic interferon-gamma production is induced by mouse hepatitis virus in interleukin-12 (IL-12)/IL-18-activated natural killer cells and modulated by carcinoembryonic antigen-related cell adhesion molecules (CEACAM) 1a receptor. Immunology 128, e551-561

73. Hosomi S, Chen Z, Baker K et al (2013) CEACAM1 on activated NK cells inhibits NKG2D-mediated cytolytic function and signaling. Eur J Immunol 43, 2473-2483

74. Kim WM, Huang YH, Gandhi A and Blumberg RS (2019) CEACAM1 structure and function in immunity and its therapeutic implications. Semin Immunol 42, 101296

75. Zhang Q, Bi J, Zheng X et al (2018) Blockade of the checkpoint receptor TIGIT prevents NK cell exhaustion and elicits potent anti-tumor immunity. Nat Immunol 19, 723-732

76. Johnston RJ, Comps-Agrar L, Hackney J et al (2014) The immunoreceptor TIGIT regulates antitumor and antiviral CD8(+) T cell effector function. Cancer Cell 26, 923-937

77. Gorvel L and Olive D (2020) Targeting the "PVR-TIGIT axis" with immune checkpoint therapies. F1000Res 9, 354

78. Wang J, Sanmamed MF, Datar I et al (2019) Fibrinogenlike protein 1 is a major immune inhibitory ligand of LAG-3. Cell 176, 334-347 e312

79. Maeda TK, Sugiura D, Okazaki IM, Maruhashi T and Okazaki T (2019) Atypical motifs in the cytoplasmic region of the inhibitory immune co-receptor LAG-3 inhibit T cell activation. J Biol Chem 294, 6017-6026

80. Merino A, Zhang B, Dougherty P et al (2019) Chronic stimulation drives human NK cell dysfunction and epigenetic reprograming. J Clin Invest 129, 3770-3785

81. Brignone C, Grygar C, Marcu M, Schakel K and Triebel F (2007) A soluble form of lymphocyte activation gene-3 (IMP321) induces activation of a large range of human effector cytotoxic cells. J Immunol 179, 4202-4211

82. Brignone C, Escudier B, Grygar C, Marcu M and Triebel F (2009) A phase I pharmacokinetic and biological correlative study of IMP321, a novel MHC class II agonist, in patients with advanced renal cell carcinoma. Clin Cancer Res 15, 6225-6231

83. Brignone C, Gutierrez M, Mefti F et al (2010) First-line chemoimmunotherapy in metastatic breast carcinoma: combination of paclitaxel and IMP321 (LAG-3lg) enhances immune responses and antitumor activity. J Transl Med 8,71

84. Nath PR, Gangaplara A, Pal-Nath D et al (2018) CD47 expression in natural killer cells regulates homeostasis and modulates immune response to Lymphocytic choriomeningitis virus. Front Immunol 9, 2985

85. Nath PR, Pal-Nath D, Mandal A, Cam MC, Schwartz AL and Roberts DD (2019) Natural killer cell recruitment and activation are regulated by CD47 expression in the tumor microenvironment. Cancer Immunol Res 7, 15471561

86. Valipour B, Abedelahi A, Naderali E et al (2020) Cord blood stem cell derived CD16(+) NK cells eradicated acute lymphoblastic leukemia cells using with anti-CD47 antibody. Life Sci 242, 117223

87. Tsao LC, Crosby EJ, Trotter TN et al (2019) CD47 blockade augmentation of trastuzumab antitumor efficacy dependent on antibody-dependent cellular phagocytosis. JCl Insight 4, e131882

88. Allard B, Longhi MS, Robson SC and Stagg J (2017) The ectonucleotidases CD39 and CD73: novel checkpoint inhibitor targets. Immunol Rev 276, 121-144

89. Neo SY, Yang Y, Record J et al (2020) CD73 immune checkpoint defines regulatory NK cells within the tumor microenvironment. J Clin Invest 130, 1185-1198

90. Wang J and Matosevic S (2019) NT5E/CD73 as correlative factor of patient survival and natural killer cell infiltration in glioblastoma. J Clin Med 8, 1526

91. Chambers AM and Matosevic S (2019) Immunometabolic dysfunction of natural killer cells mediated by the Hypoxia-CD73 axis in solid tumors. Front Mol Biosci 6, 60

92. Zheng Y, Ma X, Su D et al (2020) The roles of Siglec7 and Siglec9 on natural killer cells in virus infection and tumour progression. J Immunol Res 2020, 6243819

93. Hudak JE, Canham SM and Bertozzi CR (2014) Glycocalyx engineering reveals a Siglec-based mechanism for NK cell immunoevasion. Nat Chem Biol 10, 69-75

94. Jandus C, Boligan KF, Chijioke O et al (2014) Interactions between Siglec-7/9 receptors and ligands influence NK cell-dependent tumor immunosurveillance. J Clin Invest 124, 1810-1820

95. Hernandez-Caselles T, Miguel RC, Ruiz-Alcaraz AJ and Garcia-Penarrubia P (2019) CD33 (Siglec-3) Inhibitory function: role in the NKG2D/DAP10 activating pathway. J Immunol Res 2019, 6032141

96. Kohl U, Arsenieva S, Holzinger A and Abken H (2018) CAR $T$ cells in trials: recent achievements and challenges that remain in the production of modified T cells for clinical applications. Hum Gene Ther 29, 559-568

97. Maude SL, Laetsch TW, Buechner J et al (2018) Tisagenlecleucel in children and young adults with B-cell lymphoblastic leukemia. N Engl J Med 378, 439-448

98. Ren J, Liu X, Fang $\mathrm{C}$, Jiang $\mathrm{S}$, June $\mathrm{CH}$ and Zhao $\mathrm{Y}$ (2017) Multiplex genome editing to generate universal CAR T cells resistant to PD1 inhibition. Clin Cancer Res 23, 2255-2266

99. Georgiadis C, Preece R, Nickolay L et al (2018) Long terminal repeat CRISPR-CAR-coupled "universal" T cells mediate potent anti-leukemic effects. Mol Ther 26, 12151227

100. Liu X, Zhang Y, Cheng C et al (2017) CRISPR-Cas9mediated multiplex gene editing in CAR-T cells. Cell Res $27,154-157$

101. Shifrin N, Raulet DH and Ardolino M (2014) NK cell self tolerance, responsiveness and missing self recognition. Semin Immunol 26, 138-144

102. Cheng $M$, Chen $Y Y$, Xiao $W H$, Sun $R$ and Tian ZG (2013) NK cell-based immunotherapy for malignant 
diseases. Cell Mol Immunol 10, 230-252

103. Liu E, Tong $Y$, Dotti $G$ et al (2018) Cord blood NK cells engineered to express IL-15 and a CD19-targeted CAR show long-term persistence and potent antitumor activity. Leukemia 32, 520-531

104. Li Y, Hermanson DL, Moriarity BS and Kaufman DS (2018) Human iPSC-derived natural killer cells engineered with chimeric antigen receptors enhance anti-tumor activity. Cell Stem Cell 23, 181-192 e185

105. Rezvani K, Rouce R, Liu E and Shpall E (2017) Engineering natural killer cells for cancer immunotherapy. Mol Ther 25, 1769-1781

106. Suck G, Odendahl M, Nowakowska P et al (2016) NK-92: an 'off-the-shelf therapeutic' for adoptive natural killer cell-based cancer immunotherapy. Cancer Immunol Immunother 65, 485-492

107. Karschnia P, Jordan JT, Forst DA et al (2019) Clinical presentation, management, and biomarkers of neurotoxicity after adoptive immunotherapy with CAR T cells. Blood 133, 2212-2221

108. Veluchamy JP, Kok N, van der Vliet HJ, Verheul HMW, de Gruijl TD and Spanholtz J (2017) The rise of allogeneic natural killer cells as a platform for cancer immunotherapy: recent innovations and future developments. Front Immunol 8, 631

109. Moretta A (2002) Natural killer cells and dendritic cells: rendezvous in abused tissues. Nat Rev Immunol 2, 957964

110. Wang WX, Jiang JT and Wu CP (2020) CAR-NK for tumor immunotherapy: clinical transformation and future prospects. Cancer Letters 472, 175-180

111. Liu E, Marin D, Banerjee P et al (2020) Use of CARtransduced natural killer cells in CD19-positive lymphoid tumors. N Engl J Med 382, 545-553

112. Ruella M, Barrett DM, Kenderian SS et al (2016) Dual CD19 and CD123 targeting prevents antigen-loss relapses after CD19-directed immunotherapies. J Clin Invest 126, 3814-3826

113. Orlando EJ, Han X, Tribouley C et al (2018) Genetic mechanisms of target antigen loss in CAR19 therapy of acute lymphoblastic leukemia. Nat Med 24, 1504-1506

114. Sayitoglu EC, Georgoudaki AM, Chrobok M et al (2020) Boosting natural killer cell-mediated targeting of sarcoma through DNAM-1 and NKG2D. Front Immunol 11, 40

115. Barrow AD, Martin CJ and Colonna M (2019) The natural cytotoxicity receptors in health and disease. Front Immunol 10, 909

116. Zhang C, Oberoi $P$, Oelsner $S$ et al (2017) Chimeric antigen receptor-engineered NK-92 cells: an off-the-shelf cellular therapeutic for targeted elimination of cancer cells and induction of protective antitumor immunity. Front Immunol 8, 533

117. Dotti G, Gottschalk S, Savoldo B and Brenner MK (2014) Design and development of therapies using chimeric antigen receptor-expressing T cells. Immunol Rev 257, 107-126

118. Sadelain M, Brentjens R and Riviere I (2013) The basic principles of chimeric antigen receptor design. Cancer Discov 3, 388-398
119. Chmielewski M, Hombach A, Heuser C, Adams GP and Abken $\mathrm{H}$ (2004) T cell activation by antibody-like immunoreceptors: Increase in affinity of the single-chain fragment domain above threshold does not increase $\mathrm{T}$ cell activation against antigen-positive target cells but decreases selectivity. J Immunol 173, 7647-7653

120. Morgan RA, Yang JC, Kitano M, Dudley ME, Laurencot CM and Rosenberg SA (2010) Case report of a serious adverse event following the administration of $\mathrm{T}$ cells transduced with a chimeric antigen receptor recognizing ERBB2. Mol Ther 18, 843-851

121. Burger MC, Zhang CC, Harter PN et al (2019) CAR-engineered NK cells for the treatment of glioblastoma: turning innate effectors into precision tools for cancer immunotherapy. Front Immunol 10, 2683

122. Anderson P, Caligiuri M, Ritz J and Schlossman SF (1989) $\mathrm{Cd} 3$-negative natural-killer cells express Zeta-Tcr as part of a novel molecular-complex. Nature 341, 159-162

123. Kofler DM, Chmielewski M, Rappl G et al (2011) CD28 costimulation impairs the efficacy of a redirected T-cell antitumor attack in the presence of regulatory $\mathrm{T}$ cells which can be overcome by preventing Lck activation. Mol Ther 19, 760-767

124. Topfer K, Cartellieri M, Michen S et al (2015) DAP12 based activating chimeric antigen receptor for NK cell tumor immunotherapy. J Immunol 194, 3201-3212

125. Chang ZL and Chen YY (2017) CARs: synthetic immunoreceptors for cancer therapy and beyond. Trends Mol Med 23, 430-450

126. Alabanza L, Pegues M, Geldres C et al (2017) Function of novel anti-CD19 chimeric antigen receptors with human variable regions is affected by hinge and transmembrane domains. Mol Ther 25, 2452-2465

127. Brentjens RJ, Riviere I, Park JH et al (2011) Safety and persistence of adoptively transferred autologous CD19targeted $\mathrm{T}$ cells in patients with relapsed or chemotherapy refractory B-cell leukemias. Blood 118, 4817-4828

128. Long $\mathrm{AH}$, Haso WM, Shern JF et al (2015) 4-1BB costimulation ameliorates $\mathrm{T}$ cell exhaustion induced by tonic signaling of chimeric antigen receptors. Nat Med $21,581-590$

129. Salter Al, Ivey RG, Kennedy JJ et al (2018) Phosphoproteomic analysis of chimeric antigen receptor signaling reveals kinetic and quantitative differences that affect cell function. Sci Signal 11, eaat6753

130. Kershaw MH, Westwood JA, Parker LL et al (2006) A phase I study on adoptive immunotherapy using genemodified T cells for ovarian cancer. Clin Cancer Res 12, 6106-6115

131. Sahm C, Schonfeld K and Wels WS (2012) Expression of IL-15 in NK cells results in rapid enrichment and selective cytotoxicity of gene-modified effectors that carry a tumorspecific antigen receptor. Cancer Immunol Immunother 61, 1451-1461

132. Cichocki F, Valamehr B, Bjordahl R et al (2017) GSK3 inhibition drives maturation of NK cells and enhances their antitumor activity. Cancer Res 77, 5664-5675

133. Kagoya Y, Tanaka S, Guo TX et al (2018) A novel chimeric antigen receptor containing a JAK-STAT signaling domain mediates superior antitumor effects. Nat Med 24, 
352-359

134. Chmielewski $M$ and Abken $H$ (2017) CAR T cells releasing IL-18 convert to T-Bet(high) FoxO1(low) effectors that exhibit augmented activity against advanced solid tumors. Cell Reports 21, 3205-3219

135. Chmielewski M and Abken H (2015) TRUCKs: the fourth generation of CARs. Expert Opin Biol Ther 15, 1145-1154

136. Hurton LV, Singh H, Najjar AM et al (2016) Tethered IL-15 augments antitumor activity and promotes a stemcell memory subset in tumor-specific T cells. Proc Natl Acad Sci U S A 113, E7788-E7797

137. Wang XM, Jasinski DL, Medina JL, Spencer DM, Foster AE and Bayle JH (2020) Inducible MyD88/CD40 synergizes with IL-15 to enhance antitumor efficacy of CARNK cells. Blood Adv 4, 1950-1964
138. Mitwasi N, Feldmann A, Arndt C et al (2020) "UniCAR"modified off-the-shelf NK-92 cells for targeting of GD2-expressing tumour cells. Sci Rep 10, 2141

139. Fabian KP, Padget MR, Donahue RN et al (2020) PD-L1 targeting high-affinity NK (t-haNK) cells induce direct antitumor effects and target suppressive MDSC populations. J Immunother Cancer 8, e000450

140. Chang YH, Connolly J, Shimasaki N, Mimura K, Kono K and Campana D (2013) A chimeric receptor with NKG2D specificity enhances natural killer cell activation and killing of tumor cells. Cancer Res 73, 1777-1786

141. Imamura M, Shook D, Kamiya T et al (2014) Autonomous growth and increased cytotoxicity of natural killer cells expressing membrane-bound interleukin-15. Blood $124,1081-1088$ 